\title{
Managed environmentalism
}

Environ. Sociol. 5, 308-322 (2019)

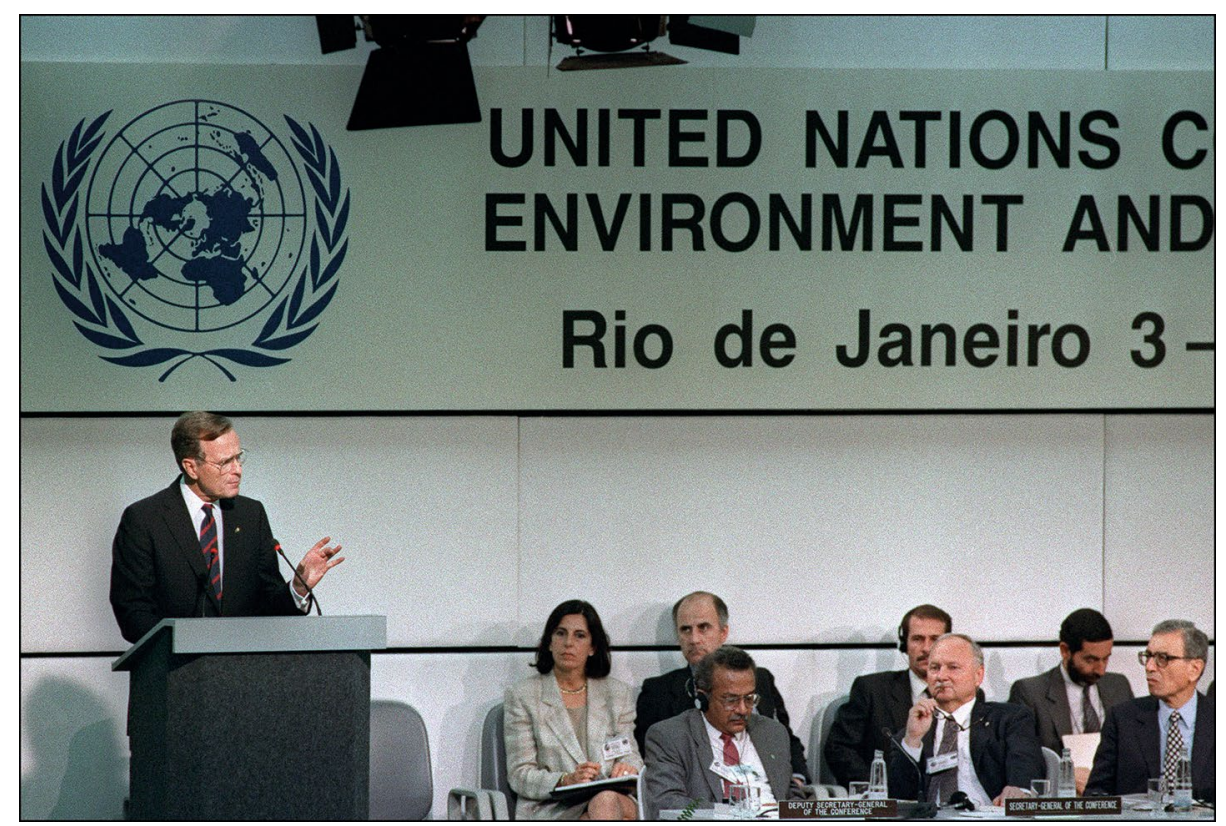

Credit: DANIEL GARCIA / Staff/ Getty

Much of the perceived history of Western environmentalism casts researchers and activists on the side of disseminating information about environmental governance but being stymied by corporations and lobbyists, such as the reaction to Rachel Carson's Silent Spring. However, public-relations firms also created and distributed a vision for responding to environmental issues - understanding how this was done is key to framing better environmental communication.

Melissa Aronczyk and Maria Isabel Espinoza at Rutgers University combined sociological theories of 'epistemic communities' with historical archives and interviews to study the impact of a publicrelations network called EnviroComm that operated between 1989 and 1997. EnviroComm was particularly influential within the European Community, but also operated in the USA and Mexico, drawing upon the expertise of numerous firms that had been involved with tobacco and oil companies. Much of their work focused on 'sustainable communication' that helped companies enter and frame discussions of environmental regulations, helping spread an 'American' style of corporate advocacy into how governance approached policy making. This epistemic community was thus able to harness and focus resources into spreading a certain type of environmental response, albeit one far softer than activists were calling for.

\section{Ryan Scarrow}

Published online: 9 August 2019

https://doi.org/10.1038/s41893-019-0369-0 